\title{
Health Professionals Standing Committee
}

Report to the General Assembly in Stockholm, June 2002

After the general assembly meeting in Prague we welcomed our new vice president, Jill Lloyd. During the year Jill attended the inaugural meeting of Polish health professionals and the International Classification of Function core conference.

\section{Education}

The education visit last year was to Hungary-at the invitation of Edina Sziraki. It was expertly organised as usual by Anne Bos. The tutors consisted of Anne Mette Langaard, Jill Lloyd, Ulla Nordenskiold, and Anne Bos. Translation was by Edina Sziraki. The programme lasted for 2.5 days and consisted of rehabilitation, patient education, spa treatment, hydrotherapy, and the value of exercises, care programmes, and splinting.

We are sorry that Anne Bos is leaving. She has made an enormous personal and professional contribution to the committee and to me and to the success of the education programme. Thank you Anne.

Now that financial support has been agreed we are ready to "launch" the format and application process for individual education visits and research proposals. The research will preferably be multidisciplinary, multinational and focus on patients.

\section{Newsletter}

Ulla Nordenskiold produced the newsletter in the Autumn of 2001, a valuable contribution for all health professionals. The task of producing this is no mean feat. We also thank Sophie Edwards and her team for a professional production.

\section{Round table meeting: strategic review}

During the Congress in Prague health professionals held their first round table meeting. This was well attended and the outcome presented to the standing committee meeting which followed.

The issues raised at the round table meeting and at the standing committee meeting highlighted the need for a strategic review of health professionals' activities in order to:

- Understand the needs of the membership

- Clarify roles and aims and identify strategies to meet these

- Identify priorities of activities.

The review was funded by the EULAR executive and facilitated by Sophie Edwards and Julia Kermode with the support of Jill Lloyd and me.

A survey of all standing committee members was undertaken. A review meeting took place in November, with six volunteers, using the information received from the survey. The strategic review report was circulated to the standing committee and EULAR executive.

The plan for the next three years has five agreed key aims which are:

l To promote high quality evidence based practice in therapeutic intervention to ensure that people with Arthritis and Rheumatism in Europe receive the best possible care.

2 To promote the unique role of the health professional within the multidisciplinary team, including clinicians and people with arthritis and rheumatism.
3 To support health professionals and their organisations and networks in Europe.

4 To facilitate the sharing of information, skills, and resources between health professionals in Europe.

5 To give a voice to health professionals in Europe through a strong, representative, and effective committee.

All these objectives and resulting activities are important.

The plan makes suggested priorities for activities over the next three years with monitoring arrangements in order to achieve them. These will be discussed and agreed at the next standing committee meeting.

\section{Final comments}

EULAR has kindly agreed to fund some management and administrative support for the committee for 2002-3, which will be provided by Sophie Edwards and coworkers. Future development of the committee will depend heavily on continued secretarial provision.

The coming year will be my last as Chair of the standing committee. I am delighted with the progress made to date and enormously excited for the future progress of health professionals.

My thanks to the standing committee, the vice president, EULAR secretariat and executive committee for their support and especially to Sophie Edwards without whose guiding hand we would have experienced difficulty in producing such a professional strategic plan.

N Price pnprice@btinternet.com 